\title{
Organizational and technological features of the modern building systems' development
}

\author{
Inna Zilberova, Konstantin Petrov*, Irina Novoselova, and Al Fatla Abdullah Neama \\ Mokhsen
}

Don State Technical University, 344010, Rostov-on-Don, Russia

\begin{abstract}
This work is devoted to the development of modern organizational and technological building systems. The paper provides a brief analysis of the current economic situation and the related changes in the construction sector. The main trends in the construction industry organizational component development associated with the introduction of modern software are considered. The scholastic and genetic algorithms for the construction process organizational components' development are highlighted. In the technological aspect, the focus is on the automation and robotization of construction processes as well as the related changes and problems. The main, according to the authors, achievements of modern technology and the possibility of their widespread use and replacement of human labor by them are considered.
\end{abstract}

\section{Introduction}

\subsection{Modern approach to the organizational and technological model choice}

The current economic situation in the world continues to be unstable. Due to the constantly emerging economic crises, any economic activity threatens to turn out to be unprofitable. The coronavirus pandemic that turned the economic situation on, has shown that it impossible to fully predict the factors that may affect the project in the long term. This means that at the moment, a competent choice of an organizational and technological model and the most complete planning are beginning to play a particularly important role, since as a result of an unfavorable outcome, it is possible to obtain not the maximum profit, as it was before, but any profit in general. Moreover, constant changes in the current legislation led to an increase in risk in the construction industry and, therefore, made certain adjustments to the existing market model and the usual supply-demand ratio.

\section{Aspects of the modern building systems' formation}

Organizational and technological solutions include not only the implementation of the construction process itself, but also various aspects of the construction companies' work.

\footnotetext{
* Corresponding author: pks81@bk.ru
} 
The organization of the modern construction companies' work should be carried out through maximum industrialization and typification, which allows not only to transfer most of the production to the plant, but also to improve the quality of products through the use of the products' narrowed range. Moreover, the typification of the nomenclature used in the construction of products reduces operating costs, cheapens repairs, leads to a decrease in the situations when, due to the lack of spare parts or the cessation of production of materials or elements used in construction, it is necessary to make more significant, quantitatively or qualitatively, repairs or, as another addition, replacement of the entire structural element. A number of researchers believe that the main necessary aspect of the formation of modern construction systems is to improve the quality of use of construction machines and mechanisms, optimize their work, minimize downtime and increase the overall efficiency of work. Particular attention should be paid to the development of new types of rationing and accounting for the work of machines and mechanisms [1]. In this area, a significant contribution can be the introduction of various BIM models and software, which allow combining several stages of design and construction in one model and, thereby, simplify work and facilitate communication between the designers of various elements of an object or engineering systems.

This and a number of other problems associated with the organizational and technological aspect of construction can be solved by the specialized software package development based on modern computing systems. When using the most popular scheduling at the moment, traditional linear planning systems are used, which are welldeservedly respected by specialists [2]. Linear systems have been used for a long time and their simplicity and efficiency make them quite relevant to this day. While simple enough, they are nevertheless effective in organizing the small projects' construction. When building significant complexes, the linear model is proportionally increased, a number of logistical and organizational restrictions are imposed. That is, when organizing the construction of large objects, linear models intended largely for manual compilation become much less relevant and they can be replaced by a modern software package.

Modern research also proposes a number of other models that make it possible to more accurately determine the time and labor costs of the construction process. The use of scholastic models makes it possible to take into account the emergence of various uncertainties that arise during the construction or reconstruction process. The distribution of probabilities in such models allows the most efficient division of money and labor resources between objects, to optimize the entire construction process [3]. Returning to the question of objects with significant areas and volumes, it can be noted that the scholastic models are allowed to achieve greater savings and time accuracy than the linear models. This feature becomes the more effective, the larger the erected object or group of objects.

Another type of information modeling is the use of genetic algorithms that make it possible to achieve a high degree of production and resources optimization by randomly combining models and finding the most effective solution [4]. These models require significant computer power, especially in the construction of large facilities or a complex of facilities, but they give an opportunity to achieve the greatest accuracy when calculating the optimal time and materials costs. These models become extremely relevant with the overall high cost of building an object, the need to consume expensive materials, as well as the use of expensive highly qualified labor.

A number of foreign researchers presented the information models for the delivery of resources from various suppliers, taking into account possible deviations from the schedule and various unforeseen circumstances [5]. These studies were continued in the Russianlanguage literature. A number of domestic researchers have created a model based on evolutionary indicators, taking into account the possibility of disruption in the supply of resources and the creation of a number of backup work schedules due to problems that have 
arisen. The authors are convinced that this model can also be used to account for various emergencies, deteriorating weather conditions, collapse of a part of the mounted structures, etc. Such models are capable of taking into account possible force majeure circumstances at the project documentation time of development and calculating the construction period, required labor costs and financial losses, taking into account such an unfavorable development of events, which is incredibly important in the current transitional stage of economic development [6]. Also, such models can become incredibly effective in the construction of facilities in hard-to-reach regions, such as the northern regions of the Russian Federation - Siberia, Kamchatka, etc. In these regions, there is a high risk of disruption in the supply of resources due to the limited transport means, the high cost of using alternative delivery systems and the seasonal cross-country ability of a number of communication routes.

All of the above-said is largely related to the organizational component of building systems. In the field of technological development, first of all, it is necessary to highlight the global trend aimed at automating most of the construction processes. Being one of the most financially and labor-intensive, the construction industry includes many technological processes with varying degrees of complexity. In this context, automation plays not only the role of reducing labor costs, but also minimizing the human factor in production in order to increase the final quality of work [7].

However, automation itself has been making its way into the construction industry for a long time. Modern researchers note that in the modern construction industry one should speak not even about automation, but about robotization of many technological processes. The most popular is the use of a robotic arm, which acts as an alternative to the human worker. However, such a technology at this stage is applicable to a greater extent in the conditions of factory production and is unlikely to replace a person at a construction site. It is also possible to cite a number of other, even more relevant developments. A robot manufactured by Odico Formwork Robotic, using hot wire cutting technology, is able to create the double-curved concrete structures, which was previously an incredibly expensive construction process and, therefore, limited the use of this structure in construction. This robot can also manufacture complex form work faster and more accurately than a human form worker. Another example is the SAM 100 developed by Construction Robotics. This robot is no longer limited by the factory working conditions. It acts as an alternative to the human bricklayer. However, not all robotic technologies are aimed at ousting humans from the production process. A wide range of rover robots or robotic assistants has been developed, equipped with cameras and sensors and capable of delivering the required tools and equipment to workers on construction sites, which can significantly increase labor productivity with the same amount of labor [8].

\section{Application of robotic technologies}

Another interesting application of robotic technology is the use of a 3D printer for the construction of the supporting frame of a building. A breakthrough is the use of contour construction, which is now being actively developed. This technology is aimed at the construction of cheap, easy-to-plan buildings in one day. Contouring is actively developing in the United States and China. In China, they were able to build a three-story house with a width of 6.4 meters using this technology. In the USA, a house with an area of over 250 square meters was "printed". A huge advantage of this technology is the possibility of widespread use of construction waste in the buildings' load-bearing structures construction. The active development of this technology suggests that in the foreseeable future it can largely alleviate the housing problem in a number of developing countries of the world. However, people in developed countries are unlikely to use this technology due to the 
limited planning possibilities and inferior quality of structures compared to the buildings erected using traditional technologies [9].

At the same time, the technological process technical component improvement leads to a number of significant problems, primarily related to such robots and mechanisms' reliability. The emergence of a new technique, recently introduced into general application, entails the emergence of new risks, that is, the adjustment of established organizational and financial models. Insufficient distribution of such mechanisms also means a small number of personnel capable of servicing and repairing this equipment. A small number of manufacturers of such mechanisms also involves a number of logistical problems [10]. Moreover, despite the rapid surge in robotization, it should be noted that most of modern robots used in the construction industry are capable of performing a very limited set of tasks, each robot is often capable of performing only one type of work, which leads to the need for use on a construction site a large group of versatile robots, linking their work with each other, which will lead to a significant complication of technological schemes, an increase in the cost of general production planning. Moreover, due to the complexity and interdependence of many processes on a construction site, the use of a large number of robots will lead to a possible halt of the entire construction process if even one robot fails. These problems indicate that robots will be introduced into the construction industry, but their field of application will remain limited in the coming decades.

\section{Conclusion}

All of the above-described can significantly modernize the organizational and technological components of the construction process, but a number of common problems also arise. First of all, the problems of a significant lag of the regulatory framework behind modern construction trends and the lack of legal regulation of new developments are worth mentioning. Another major problem is the recognized conservatism and static nature of the construction industry, that is, the job producers are very reluctant to agree to the use of the new, not yet fully studied developments, especially without the possibility of short-term profit. The current economic situation shows that the risks associated with the introduction of new systems can threaten the very existence of a number of construction firms, which is unlikely to stimulate organizations to introduce new technologies and organizational schemes and invest heavily in this.

\section{References}

1. V.V. Kostyuchenko, Bulletin of Eurasian Science 5 (18), (2013) https://cyberleninka.ru/article/n/osnovy-formirovaniya-organizatsionnotehnologicheskih-stroitelnyh-firm.

2. I. Zilberova, K. Petrov, M. Artsishevsky. IOP Conference Series: Materials Science and Engineering 753 (3), 042020 Doi: 10.1088/1757-899X/753/4/042020.

3. S.A. Bolotin, I.Yu. Meshchaninov, Bulletin of Higher Educational Institutions. Building 2 (602), 38-42 (2009)

4. V.Ya. Mishchenko, D.I. Emelyanov, A.A. Tikhonenko, Industrial and Civil Engineering 11, 76-78 (2013)

5. E.O. Mirgorodskaya, I.V. Novoselova, V.Y. Steiner, Materials Science Forum 931, 1160-1164 (2018)

6. N.S. Kurchenko, A.V. Alekseytsev, S.S. Galkin, Vestnik MGSU 10, 120-130 (2016) 
7. S.I. Evtushenko, A.G. Bulgakov, V.A. Vorobiev, Automation and robotization of construction: Textbook (Rior, Moscow, 2017)

8. B.G. Chachko, Colloquium-journal 3 (55), 26-39 (2020) DOI: 10.24411/2520-69902020-11294.

9. L.B. Zelentsov, L.D. Mailyan, IOP Conference Series: Earth and Environmental Science (2017) https://www.scopus.com/inward/record.url?eid=2-s2.085035072916\&partnerID=40\&md5=f800ab885584ca1e09f61202c0e3f3e4.

10. V.V. Kostyuchenko, Engineering Journal of Don 4 (43), (2016) ivdon.ru/ru/magazine/archive/n4y2016/3920 